\title{
Comparative Analysis of Conventional and Waste Polyethylene Modified Bituminous Mixes
}

\author{
A New Dimension of Effective Environmental \& Waste Management
}

\author{
Dr. Muhammad Bilal Khurshid \\ Military College of Engineering (MCE) \\ National University of Sciences and Technology (NUST) \\ NUST Campus, Risalpur- 24080, Pakistan \\ mbilal@mce.nust.edu.pk \\ Dr. Muhammad Irfan \\ National Institute of Transportation (NIT), \\ School of Civil and Environmental Engineering (SCEE), \\ National University of Sciences and Technology (NUST), \\ Sector H-12, Islamabad - 44000, Pakistan \\ drirfan-nit@nust.edu.pk
}

\author{
Dr. Sarfraz Ahmed \\ Military College of Engineering (MCE) \\ National University of Sciences and Technology (NUST) \\ NUST Campus, Risalpur- 24080, Pakistan \\ sarfraz70@gmail.com \\ Engr. Sajid Mehmood \\ Military College of Engineering (MCE) \\ National University of Sciences and Technology (NUST) \\ NUST Campus, Risalpur- 24080, Pakistan \\ sajid1001s@yahoo.com
}

\begin{abstract}
Increase in road traffic in combination with insufficient maintenance due to shortage in funds causes rapid deterioration of the roads. To alleviate this process, several measures may be effective, such as, use of better quality materials, use of cost-effective construction methods, dedicated funds for maintenance, improved and innovative roadway design. With this perspective, this research aimed at exploring the potential prospects of waste plastic beverage bottles made of "High Density Polyethylene (HDPE)" to enhance asphalt mix properties as a polymer. Objectives of this research also included determining the best method of adding polymer/HDPE in asphalt mix. Marshall Mix design method was used to determine the optimum bitumen content and then modified mix properties were tested. The research results indicate that dry mix method yields better asphalt mix properties. The optimum content of HDPE was found to be $8 \%$ by the weight of optimum bitumen content. Addition of HDPE in asphalt mix is found to increase the stability, rutting resistance, and load bearing capacity of asphalt mix in comparison to conventional (unmodified) asphalt mix. Benefits of using polyethylene modified asphalt mix include; safe, efficient and environment friendly disposal of waste plastics/waste management, long lasting roads withstanding heavy traffic loads and cost-effectiveness in road construction. Economic analysis showed that addition of waste polyethylene in asphalt mix lead to a saving of Rs. $141,200.00$ per lane $\mathrm{km}$ in comparison to using conventional (unmodified) asphalt mix in road construction. The analysis and results of this research can effectively be used to greatly improve and economize the road construction and to improve the waste management.
\end{abstract}

Index Terms-Polyethylene, Bituminous Mixes, Waste Management, Rutting, Marshall Stability.

\section{INTRODUCTION}

Increase in road traffic in combination with insufficient maintenance due to shortage in funds causes rapid deterioration of the roads. To alleviate this process, several measures may be effective, such as, use of better quality materials, use of costeffective construction methods, dedicated funds for maintenance, improved and innovative roadway design. Several factors influence the performance of flexible courses, e.g., the properties of the components (binder, aggregate and additive) and the proportion of these components in the mix [1]. Bitumen can also be modified by adding different types of additives. One of these additives is the polymer $[1,2]$.

The addition of polymers typically increases the stiffness of the bitumen and improves its temperature susceptibility. Increased stiffness improves the rutting resistance of the mixture in hot climates and allows the use of relatively softer base bitumen, which in turn, provides better low temperature performance [2, 3]. Polymer modified binders also show improved adhesion and cohesion properties [3-6]. Polymers can also be added to the asphalt concrete mixtures to form an aggregate coating material. The coatings would enhance surface toughness of the aggregates and thus, produce asphalt mixtures with superior engineering properties $[6,7]$.

The growth in various types of industries together with population growth has resulted in enormous increase in production of various types of waste materials, world over. The creation and disposal of non-decaying waste materials such as Blast Furnace Slag, Fly-ash, Steel Slag, Scrap Tires, Plastics, etc. have been posing challenging problems in developed as well as in developing countries [7-11].

Use of plastic beverage bottles has become a common practice all over the world. However the disposal of the waste plastics, specially the plastic bottles in large quantities has been a problem and is of great concern, particularly in big cities. They either get mixed with municipal solid waste and or thrown over land area. A very small portion of waste plastic bottles are recycled and major part is either incinerated or left untreated on open lands [10,11]. The latter methods are indeed not eco-friendly. Under this circumstance, an alternate use for the waste plastics is also the need of the hour [7,11]. Mixing up of these waste plastic bottles with other bio-degradable 
organic waste materials in the garbage of the urban areas has been the main cause of the problem [11].

In case it is possible to find useful application for the waste plastics, there will be substantial scrap value for this waste product and therefore they will be collected and sold by interested persons, instead of being littered or thrown out in the dust bins or into the road side drains. As an initiative the study on the possible use of the waste plastic bottles with the bituminous mixes has been be carried out in this project.

Keeping the aforementioned aspects of pavement performance and waste management in perspective, this study aims to determine the best method of adding high density polyethylene (waste plastic bottles) (HDPE) and its optimum percentage to enhance asphalt mix properties. This study also presents a comparison of high density polyethylene (HDPE) modified Hot Mix Asphalt (HMA) with conventional HMA in terms of Marshall stability, flow and rutting resistance evaluated by Hamburg Wheel Tracking test. The economic analysis determines the cost effectiveness of using HDPE modified HMA in comparison to conventional (unmodified) HMA.

\section{EXPERIMENTAL DESIGN}

\section{A. Research Methodology}

Experimental phase of this research starts with the unmodified bitumen and aggregates quality tests. The optimum asphalt content is then worked out using Marshall Stability mix design process on control/conventional HMA samples. HDPE modified bitumen and aggregates quality tests are then performed to explore the effects of variation of polymer (HDPE) content (i.e. \% by weight of optimum asphalt content) on the performance of these materials. HDPE modified samples are then prepared by adding HDPE in the mix in different percentages by weight of optimum asphalt content and optimum HDPE content (i.e. \% by weight of optimum asphalt content) is then determined basing of Marshall Stability criterion.

Wet and dry processes (for mixing polymer in HMA) are performed to explore the effects of variation of polymer content in HMA and finding out the optimum polymer content on the basis of Marshall Stability. Lastly, Hamburg Wheel Tracking test is carried out to determine the rutting resistance of both control and modified samples. Economic analysis is then carried out to evaluate cost effectiveness of using HDPE modified HMA in comparison to conventional (unmodified) HMA. Based on results of performance evaluation and cost effectiveness analysis, a detailed comparative analysis of modified (polymer added HMA) and unmodified (conventional) HMA is then carried out which consequently leads the study to conclusions and recommendations.

\section{B. Materials and Test Results}

Asphalt binder 80/100 was used in this research. The coarse and fine aggregates used were crushed limestone quarried from Margalla as per National Highway Authority Pakistan Class-A specifications [12]. In this investigation, HDPE in the shredded form (passing $4.75 \mathrm{~mm}$ sieve) in varying percentages (by the weight of optimum asphalt content) was used as a modifier in the mix. Shredded HDPE (plastic bottles), uncoated and HDPE coated aggregates used in this study are shown in Figure 1.

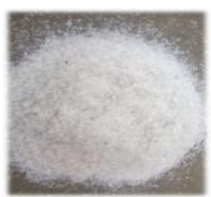

a. Shredded HDPE

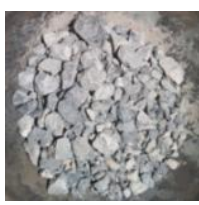

b. Uncoated Aggregates

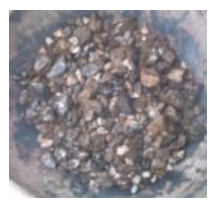

c. HDPE Coated Aggregates
Fig. 1. Shredded HDPE, uncoated and HDPE coated aggregates

Conventional tests including penetration [13], Ductility [14], Softening Point (SP), Flash Point (Fh.P) and Fire Point (Fr.P) [15] were performed on the unmodified bitumen to check its adequacy for use in HMA and found to meet the standard specifications.

Aggregate wear resistance and relative strength properties were determined using Los Angeles Abrasion value (LAAV), AASHTO T 96 and Impact Tests [16]. Table 1 provides comparison of these properties in context of uncoated and HDPE coated aggregates. It is observed that coated aggregates with $8 \%$ HDPE (i.e. \% by weight of optimum asphalt content) are $58 \%$ more wear resistant (i.e. decrease in LAAV from $23.28 \%$ to $9.85 \%$ ) and have $59 \%$ improvement in their strength (i.e. decrease in impact value from $12 \%$ to $4.88 \%$ ).

TABLE I. Summary of Test Results Performed on Aggregates

\begin{tabular}{|c|c|c|}
\hline $\begin{array}{c}\text { \% of } \\
\text { HDPE }\end{array}$ & $\begin{array}{c}\text { Los Angeles } \\
\text { Abrasion Value } \\
\text { ( \% ) }\end{array}$ & $\begin{array}{c}\text { Aggregate Impact } \\
\text { Value ( \% ) }\end{array}$ \\
\hline 0 & 23.28 & 12 \\
\hline 2 & 21.62 & 10.2 \\
\hline 4 & 18.84 & 8.66 \\
\hline 6 & 15.22 & 6.28 \\
\hline 8 & 9.80 & 4.88 \\
\hline
\end{tabular}

\section{Preparation of Control Samples}

Marshall mix design was adopted to determine the optimum bitumen content of the mixture. The Marshall stability and flow test provides the performance prediction measure for mixture's stability, load carrying capacity and resistance to permanent deformation. Total of 18 samples (three samples for each \% of bitumen) were prepared to find the optimum asphalt binder content with varying percentages of bitumen $(3.5,4,4.5,5,5.5$ and $6 \%$ ). Optimum asphalt binder content was found out to be $5 \%$. 


\section{Preparation of HDPE Modified HMA Samples}

Marshall mix design process was repeated to determine the optimum polymer content in the binder. Percentage of the HDPE yielding the highest Marshall Stability was selected as an optimum percentage of the polymer. Six proportions $(4,6,8,10,12$, and $14 \%)$ of HDPE by weight of the optimum binder content $(5 \%)$ were selected to be tested for dry process and for wet process four proportions of polyethylene by weight of optimum binder content $(5 \%)$ were selected to be evaluated $(0.5,1.0,1.5$ and $2.0 \%)$. It is important to note that the total percentage of binder in the mix remained constant $(5 \%)$ for unmodified and modified mixtures. Meaning thereby the amount of bitumen was reduced proportional to the percentage of the polymer used e.g. for a mix with $2 \%$ polymer the amount of bitumen was reduced by $2 \%$ by weight of the binder used in the mix.

1) Wet Process: In the wet process, shredded HDPE was added to bitumen at $160^{\circ} \mathrm{C}$. This process did not yield a homogenous bituminous mix with prominent separated solid deposits/pieces of mix. Therefore wet process was not adopted for this study.

2) Dry Process: In this process aggregates are heated to $170^{\circ} \mathrm{C}$ and then above mentioned percentages of shredded HDPE are added and mixed to coat the aggregates. After coating the aggregates adjusted/reduced amount of unmodified binder was used to manufacture the modified mixture in this process. Results presented in Figure 2 indicate that $8 \%$ addition of HDPE and corresponding reduction in the amount of binder yields the most stable mix as determined by Marshall Stability parameter. The Marshall Stability value increases from $10.25 \mathrm{KN}$, at $0 \% \mathrm{HDPE}$, to $17.35 \mathrm{KN}(70 \%)$ at $8 \%$ of HDPE and then starts decreasing. It is observed that dry process can utilize higher percentages of waste plastic, reduces the amount of binder required in the mix correspondingly and produce more stable mix compared to the control mix.

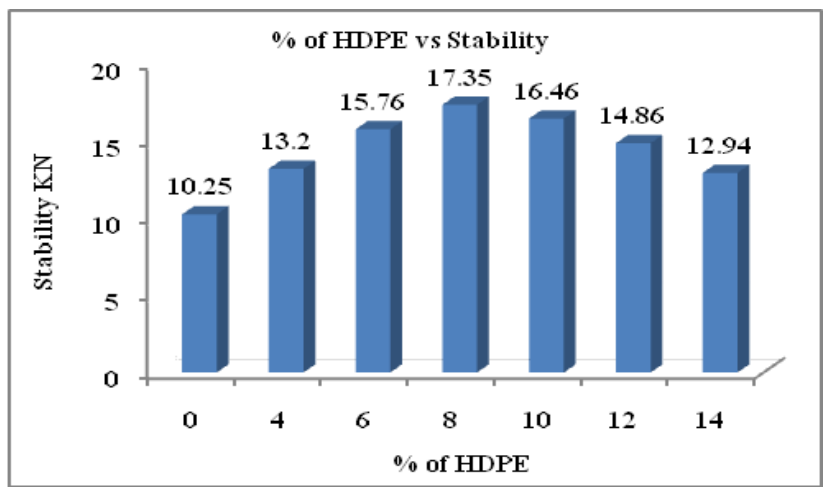

Fig. 2. Comparison of $\%$ of polymer vs. Marshall stability value

\section{E. Effect of Binder Content of Mixture Properties}

The effect of variation of the bitumen content in the waste plastics-bitumen-aggregate mixture was also evaluated in this study. The binder content used in the mix was 4.0, 4.5, 5.0 \& $5.5 \%$ for both uncoated and HDPE coated aggregates using $8 \%$ HDPE. Three replicates were prepared and tested for each category. It is observed that stability of the modified asphalt concrete mixtures is higher than the control mixture. Comparison of control and modified mixture confirms that $5.0 \%$ binder content results the most stable mix for both cases as illustrated in Figure 3.

Also it was observed in this study that the flow value decreases from $3.03 \mathrm{~mm}$, at $0 \%$ HDPE, to $2.67 \mathrm{~mm} \mathrm{(12 \%}$ decrease) at $8 \%$ of HDPE.

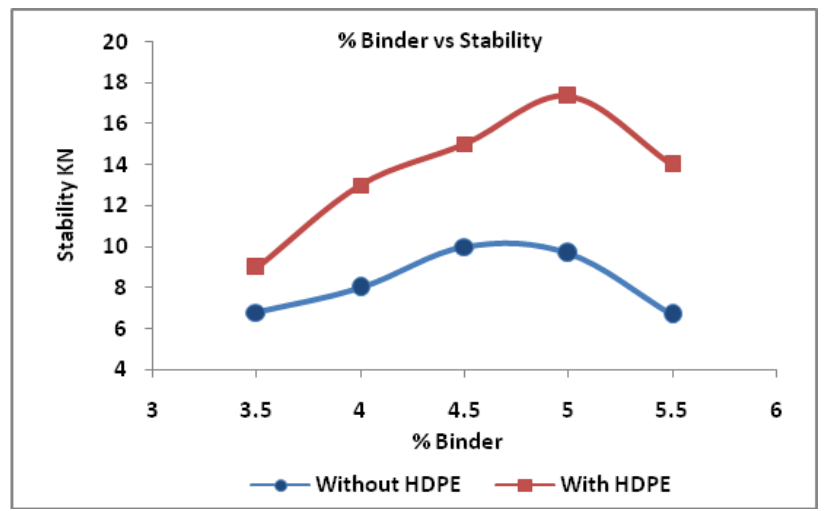

Fig. 3. Comparison of $\%$ of binder vs. Marshall stability

\section{F. Evaluation of Rutting Susceptibility of Mixtures}

Rutting susceptibility of control and HDPE modified mixtures was evaluated by Hamburg Wheel Tracking (HWT) test in accordance with AASHTO $\mathrm{T} 324$ [17]. Roller compacted slab were tested in dry condition at $45^{\circ} \mathrm{C}$ [18]. Both; unmodified and modified samples were prepared at an optimum binder content of 5.0\%. For control mix uncoated aggregates were utilized whereas coated aggregated with $8 \%$ HDPE were used for modified mixture using dry fabrication process. HWT test results presented in Figure 4 indicate that modified mixes containing HDPE are less susceptible to permanent deformation (rutting) as compared to conventional bituminous mix.

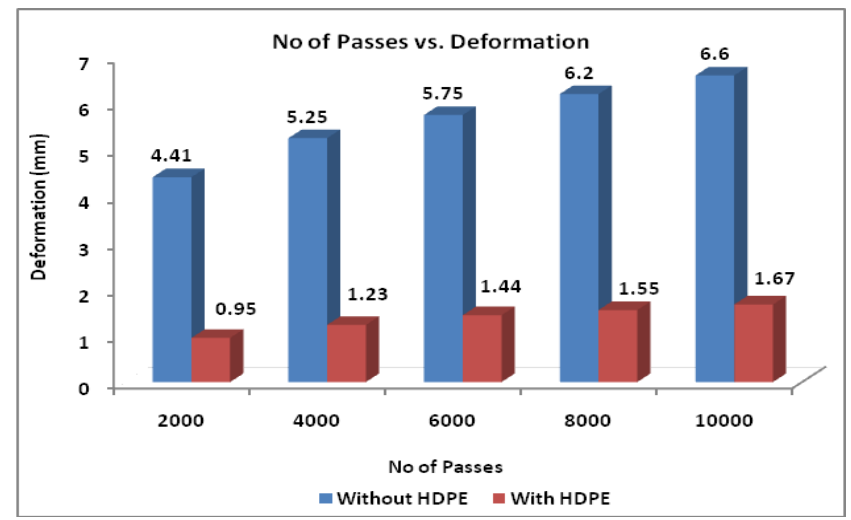

Fig. 4. HWT test results for control and HDPE modified mixtures 


\section{ECONOMIC ANALYSIS}

Economic analysis was carried out considering the material requirement for paving 4 inch thick wearing course on standard 12 feet wide lane of one kilometer length roadway section. Using HDPE content of $8 \%$ by weight of bitumen will save the $8 \%$ bitumen. Having surveyed many of the recycling agencies and municipal waste management agencies, the processing cost of waste plastic bottles (including the collection cost, cleaning \& shredding cost) was estimated to be Rupees (Rs) 40 per $\mathrm{kg}$.

It was found that $8 \%$ percent of the required bitumen can be replaced with waste plastic (HDPE) thus reducing the cost by approximately Rs.141, 200.00 per kilometer per lane in comparison to using conventional (unmodified) asphalt mix in road construction

\section{CONCLUSIONS}

Present study leads to following conclusions:

- HDPE coating of aggregates increases abrasion and impact resistance of aggregates thus improving strength and wear resistance properties of the treated aggregates. Moreover polymer coating reduces its affinity for water and may improve stripping susceptibility.

- Mixture modification using 8\% shredded HDPE improves the Marshall Stability of the mixture by $70 \%$ thus increasing it rutting resistance and load carrying capability. HWT test results also confirm that modified mixture has higher resistance to permanent deformation (rutting).

- Dry Process (polymer coating of aggregates) is more useful as compared to Wet Process (adding polymer in the binder) for manufacturing modified mixtures, as it can accommodate higher amount of waste plastic as modifier and results more stable mixtures.

- Direct addition of HDPE into heated bitumen (wet process) did not yield a homogeneous bituminous mix with prominent separated solid deposits/pieces of mix. Therefore, wet process was found to be unsuitable for use in preparation of HDPE modified asphalt mix, unless some other chemicals/additives are also used in wet process, which may be explored in future research.

- The use of waste plastics as asphalt mixture modifier ensures its safe, useful and environmental friendly disposal.

- Use of HDPE in HMA is likely to cause considerable savings. In this study HDPE addition was estimated to cause a saving of Rs.141, 200.00 per kilometer per lane in comparison to using conventional (unmodified) asphalt mix in road construction.

- Use of waste polyethylene in HMA is expected to yield better and enhanced waste management and better city hygiene and environment.

- Basing on the results of this study it is revealed that HDPE modified HMA is expected to exhibit better load carrying capacity, improved serviceability/pavement performance, greater resistance to rutting, longer service life, reduced maintenance and indeed reduced life cycle cost.

\section{REFERENCES}

[1] Subagio, B.S., Kosasih, D., Busnial, and Tenrilangi, D. "Development of stiffness modulus and plastic deformation characteristics of porous asphalt mixture using tafpack super". Proceed. Eastern Asia Soc. Transportation Studies, 5: pp. $803-812,2005$.

[2] Awwad, M. T., and Shbeeb, L. "The use of polyethylene in hot asphalt mixtures". American Journal of Applied Sciences 4 (6): pp. 390-396, 2007.

[3] Coplantz, J.S., Yapp, M. T., and Finn, F. N. "Review of relationships between modified asphalt properties and pavement performance". SHRP-A-631, Strategic Highway Res. Program, National Res. Council Washington, USA, 1993.

[4] Newman, K. "Polymer-modified asphalt mixtures for heavyduty pavements: fatigue characteristics as measured by flexural beam testing". FAA Worldwide Airport Technol. Transfer Conf. Atlantic City, New Jersey, USA, 2004.

[5] Hansen, K. R., Robert B. M., Brian P., and Stonex, A. "Current and future use of non bituminous components of bituminous paving mixtures". Committee on Characteristics of Non bituminous Components of Bituminous Paving Mixtures: A2D02. Onlinepubs.trb.org/ online pubs /millennium /00079.pdf.

[6] Robin L. Schroeder. "The use of recycled materials in highway construction", Journal, Public Roads, Vol. 58, No. 2, 1994.

[7] Amit G., Zamre, G. S., Renge, V. C., Bharsakalea, G. R., and Tayde, S. "Utilization of waste plastic in asphalting of roads". Sci. Revs. Chem. Commun.: 2(2), pp. 147-157, 2012.

[8] Sunil Bose and Sridhar Raju, "Utilization of Waste Plastic in Bituminous Concrete Mixes", Roads and Pavements, Vol. 3, 2004.

[9] Yue, H., Bird R. N. and Oliver Heidrich, A Review of the Use of Recycled Solid Waste Materials in Asphalt Pavements Resources, Conservation and Recycling, 52, pp.58-73, 2007.

[10] Bindu, C. S. and Beena, K. S. "Waste plastic as a stabilizing additive in stone mastic asphalt". Int. J. Engg. Tech., 2(6), pp. 379-387, 2010.

[11] Pakistan Environmental Protection Agency. "Solid Waste Management in Pakistan". http://www.environment.gov.pk. Accessed 25 Jan 2012.

[12] National Highway Authority Pakistan Highway Design Specifications. http://nha.gov.pk/. Accessed 15 Feb 2012.

[13] ASTM 2000, Standard Test Method for Penetration of Bitumminous Materials, D5-97, Annual Book of Standards, Vol.04.03,Eston, MD,USA,2000.

[14] ASTM D113 - 07 Standard Test Method for Ductility of Bituminous Materials.

[15] ASTM 2000, Test Method for Softening Point of Bitumen (Ring -and- Ball Apparatus), D36-06, Annual Book of ASTM Standards, Vol.04.04.

[16] AASHTO T 96-02 Standard Method of Test for Resistance to Degradation of Small-Size Coarse Aggregate by Abrasion and Impact in the Los Angeles Machine.

[17] AASHTO T 324: Standard Method of Test for Hamburg WheelTrack Testing of Compacted Hot Mix Asphalt (HMA)

[18] Fernando, M.J. and Guirguis, H.R. (1984) Natural rubber for improved surfacing, Proceedings 12th ARRB conference, Part 2 , pp. 121-130. 